J. Dairy Sci. 95:4921-4930

http://dx.doi.org/10.3168/jds.2011-4913

(C) American Dairy Science Association ${ }^{\circledR}, 2012$.

\title{
Molecular epidemiology of Staphylococcus aureus mastitis in dairy heifers
}

\author{
K. L. Anderson, ${ }^{\star 1}$ R. Lyman, ${ }^{\star}$ K. Moury, ${ }^{* 2}$ D. Ray, ${ }^{\star 3}$ D. W. Watson, $\dagger$ and M. T. Correał \\ *Milk Microbiology and Mastitis Laboratory, \\ fDepartment of Population Health and Pathobiology, College of Veterinary Medicine, and \\ †Department of Entomology, College of Agriculture and Life Sciences, North Carolina State University, Raleigh 27607
}

\begin{abstract}
The specific purpose was to investigate the possible interrelationships of genotypes of Staphylococcus aureus found in mammary glands, horn flies, and extramammary sites on 3 southeastern US dairies. A total of 1,228 samples were obtained from various sources on the 3 dairy herds, each of which had a history of Staph. aureus mastitis. Dairy herds studied had access to pasture, and samples were collected during the summer when horn flies (Haematobia irritans) were active. Samples collected included milk samples from all lactating herd cows, colostrum samples from heifers calving during the study period, heifer body sites (mouth, nostrils, and teats), the heifer environment (water, feed, and soil/ vegetation/pasture), horn flies, and humans (hands and nostrils). Isolation of Staph. aureus was attempted from all samples, with isolates subjected to genotypic analysis using pulsed-field gel electrophoresis. A total of 244/1228 (or 19.9\%) of all samples were positive for Staph. aureus. For milk samples, 52/383 (or 13.6\%) of samples were Staph. aureus positive, and 70/411 (or $17.0 \%$ ) of heifer quarter colostrum samples were positive. Horn fly samples were frequently positive, with over one-half $(29 / 52$, or $55.8 \%)$ of samples positive for Staph. aureus. Staphylococcus aureus obtained during the study comprised isolates from 12 different genotype groups as defined in this study. Identical genotypes were obtained from horn flies, heifer colostrum samples, and cow milk samples. Group B genotypes were shared among flies, heifer colostrum samples, body sites, and cow milk samples, whereas group A genotypes were common to the same sample locations and body sites but rarely (once) found in horn flies. We conclude, based upon the finding of identical pulsedfield gel electrophoresis genotypes in flies, heifer body
\end{abstract}

\footnotetext{
Received September 8, 2011.

Accepted April 27, 2012.

${ }^{1}$ Corresponding author: kevin_anderson@ncsu.edu

${ }^{2}$ Current address: Yergey, Stewart, Vallance \& Associates, Chartered, 3664A Whiskey Bottom Road, Laurel, MD.

${ }^{3}$ Current address: Mountain View Veterinary Services, 4035 McClay's Mill Rd, Shippenburg, PA.
}

sites, and heifer colostrum samples, that flies and heifer body sites could be important sources of Staph. aureus for heifer intramammary infections.

Key words: Staphylococcus aureus, mastitis, heifer, molecular epidemiology

\section{INTRODUCTION}

Staphylococcus aureus is the most common cause of chronic contagious mastitis in US dairy herds (Fox et al., 2001). The USDA found that $43 \%$ of bulk tank milk samples on US dairy operations were culture positive for Staph. aureus (Lombard et al., 2008), and the organism has been reported as a cause of IMI in cows in $>80 \%$ of US dairy herds (Roberson et al., 1998). Heifers are an important source of new Staph. aureus IMI, representing almost one-third of new cases of Staph. aureus mastitis in dairy herds (Roberson et al., 1994b, 1998; Oliver et al., 2005). At parturition, a range of 2 to $50 \%$ of heifers may calve with Staph. aureus IMI, depending upon the herd and region of country (Roberson et al., 1994b; Oliver et al., 2005).

To understand and control Staph. aureus mastitis in heifers, it is important to determine the probable source(s) of IMI for heifers. Staphylococcus aureus mastitis is most commonly transmitted cow to cow, primarily at milking time. When an infected cow is milked, the next cows milked with that unit are at increased risk of acquiring Staph. aureus mastitis. However, calving heifers have not been exposed to the milking process, so sources of Staph. aureus other than the milking equipment are involved.

Considerable investigation into the epidemiology and risk factors for Staph. aureus IMI has been done in heifers. Prior studies of the epidemiology of Staph. aureus in dairy heifers have identified Staph. aureus in sites as diverse as heifer teat skin samples, heifer external teat orifices, housing, feedstuffs, humans, nonbovine animals, air, and equipment, as well as from bedding, insects, and water (Matos et al., 1991; Roberson et al., 1992, 1994b, 1998; Wegener et al., 1993; Owens et al., 1998; Fox et al., 2001; Oliver et al., 2005; NMC, 2012). Both Haveri et al. (2008) and Artursson et al. 
(2010) have studied the epidemiology of Staph. aureus mastitis in herds using pulsed-field gel electrophoresis (PFGE) on Staph. aureus isolates. Both found that one PFGE type predominated per herd and that isolates from extramammary sites could be found which were indistinguishable from those from intramammary sites. Rajala-Schultz et al. (2010) compared heifer isolates of Staph. aureus to those from infected cows in the same herds using PFGE. They found most heifer isolates were closely related to cow isolates. Oliver et al. (2005) identified the presence of Staph. aureus in lactating cows in the herd and absence of fly control as important risk factors for heifer mastitis. Evidence indicates that the horn fly (Haematobia irritans) is a potential vector in transmission of Staph. aureus IMI (Owens et al., 1998; Oliver et al., 2005). High concentrations of Staph. aureus $\left(>10^{7} \mathrm{cfu} / \mathrm{mg}\right.$ of scab material) have been found in scabs on heifer teats, serving as a source of the organism, with potential involvement of flies in transmission (Oliver et al., 2005).

Horn flies are a particularly significant problem in the southern and southeastern United States where cattle have access to pasture. Immature stages of the horn fly develop in undisturbed dung pats in the pasture (Bruce, 1964). The adult horn fly takes up to 20 blood meals/d, and is capable of causing marked teat injury, as indicated by sores and lesions on teats (Soulsby, 1968; Merck \& Co. Inc., 2005). With heavy populations, horn flies can cause significant damage to teats and may be important in transmitting Staph. aureus mastitis. Figure 1 illustrates horn fly feeding and skin damage as a potential mechanism for the introduction of Staph. aureus IMI in heifers.

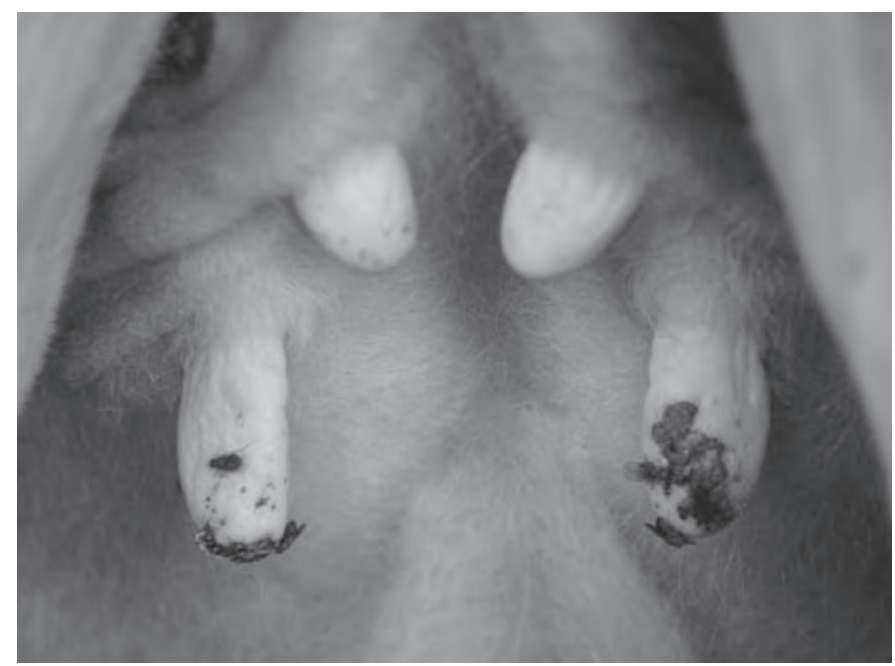

Figure 1. Horn fly feeding and skin damage.
Our specific purpose was to study the possible interrelationships of genotypes of Staph. aureus found in mammary glands, horn flies, and extramammary sites on 3 dairies with a history of Staph. aureus mastitis. We used PFGE to identify Staph. aureus genotypes. Specifically, we compared Staph. aureus genotypes found in cow milk or heifer colostrum samples to those found on heifer body sites and the environment, including horn flies.

\section{MATERIALS AND METHODS}

\section{Regulatory Compliance}

This research was approved by the North Carolina (NC) State University Institutional Animal Care and Use Committee (Raleigh). Collection of human hand and nasal samples was also approved by the NC State University Institutional Review Board.

\section{Herds}

Sampling locations were $3 \mathrm{NC}$ dairies with prior histories of heifers calving with Staph. aureus IMI. Sampling took place between June 2006 and July 2007. Herd 1, with 142 milking cows, was primarily pasture based and received supplemental grain concentrate, silage, and hay fed as needed (Table 1). All calving in herd 1 occurred primarily between August and December. Herd 1 heifer inventory (170 head) was partitioned into 4 groups: hutch, juvenile, breeding age, and bred heifers (Table 2). Herds 2 and 3 (128 and 143 milking cows, respectively) were housed in freestall facilities and cows were fed a TMR composed of grain concentrate, corn silage, and minerals, with access to hay (Table 1). Cows on both dairies had access to pasture during a portion of the day. Herds 2 and 3 included 107 and 108 heifers, respectively (Table 2 ).

Cows in all herds were milked in parlors twice per day, with application of mastitis control programs consistent with those established by the National Mastitis Council (NMC; http://www.nmconline.org), current at the time of consideration. This included consistent use of postmilking teat dipping, dry cow therapy, periodic milking machine maintenance, and proper milking and intramammary treatment procedures.

\section{Sampling and Microbiology}

Milk and Colostrum Samples. Cow composite quarter milk samples were aseptically collected from all milking cows present in each herd once during the study period. This included 117, 118, and 148 cow samples from herds 1,2 , and 3 , respectively (Table 3 ). 
Table 1. Herd characteristics from DHIA records at approximately midpoint in the study

\begin{tabular}{lccc}
\hline Item & Herd 1 & Herd 2 & Herd 3 \\
\hline Milking cows & 142 & 128 & 143 \\
Rolling herd average (kg) & 5,944 & 9,598 & 10,229 \\
Milk/cow per day (kg) & 18.9 & 26.1 & 28.9 \\
Average linear SCC score & 3.0 & 3.3 & 3.1 \\
Average weighted SCC/mL & 216,000 & 249,000 & 263,000 \\
\hline
\end{tabular}

Quarter milk (colostrum) samples were collected consecutively, in order of calving, from heifers within 3 to $4 \mathrm{~d}$ after calving $(\mathrm{n}=44,38$, and 24 heifers with 171 , 145, and 95 total quarters sampled for herds 1, 2 and 3, respectively; Table 3).

Procedures for bacteriologic culture were consistent with those previously published (Hogan et al., 1999). Aseptically collected milk and colostrum samples were plated within $24 \mathrm{~h}$ of collection or frozen for $\leq 1$ wk at $-20^{\circ} \mathrm{C}$ and then quick thawed and plated. Milk samples were vortexed and $0.01 \mathrm{~mL}$ of milk was plated on trypticase soy agar (TSA) with 5\% sheep blood (BBL TSA II 5\% SB agar; Becton, Dickinson and Co., Sparks, $\mathrm{MD})$. Plates were incubated at $36^{\circ} \mathrm{C}$ and examined after 24 and $48 \mathrm{~h}$ of incubation. Creamy, grayish-white, or golden-yellow pigmented colonies of catalase- and coagulase-positive gram-positive cocci that were capable of complete, incomplete, or both complete and incomplete hemolysis were identified as Staph. aureus (Hogan et al., 1999). Similar colonies with no hemolysis were confirmed as Staph. aureus using a commercial staphylococcal identification system (API Staph identification system; bioMérieux Inc., Durham, NC).

Heifer Sites. To obtain representative samples on each dairy, a minimum of 3 to 5 heifers were sampled in each group present, with a goal of sampling $20 \%$ of each group, up to a maximum of 10 heifers per group. Nostrils, mouth, and teat samples were collected from 25 , 25 , and 24 heifers on dairies 1, 2, and 3, respectively. A new sterile transport media swab (BD BBL Culture Swab; Becton, Dickinson and Co.) was used to sample each heifer body site. Fresh sterile gloves were worn for each heifer, and gloves were sprayed with disinfectant (HDQ Neutral; Spartan Chemical Co. Inc., Maumee, $\mathrm{OH})$, followed by isopropanol, and then dried, between site sampling on each heifer.
Nostrils. A transport swab was used to swab inside the right and left nostrils of heifers. The swab was placed approximately 1 to $2 \mathrm{~cm}$ inside the nostril from the most rostral aspect of the nose, holding the swab perpendicular to the opening of the nostril. The swab was rolled completely around the circumference of each nostril with light pressure.

Mouth. For the mouth samples, a single swab was used to sample the right commissure and cheek as well as the tongue of each heifer. The swab was used to sample the right commissure of the mouth, making 2 complete revolutions; the swab was then held parallel to the long axis of the heifer's body and placed approximately $2 \mathrm{~cm}$ into the cheek area before being rotated for 2 complete revolutions. Using the same swab, it was then held perpendicular to the long axis of the body and rotated on the rostral $2 \mathrm{~cm}$ of the tongue for 2 revolutions.

Teats. A single transport swab moistened with sterile saline was used to swab the middle of the barrel of right front and right rear teats. The swab was held perpendicular to the long axis of the body and 2 complete revolutions were made on the middle of the barrel of the teat of the right front and right rear teats. The swab was then held perpendicular to the long axis of the body, and 2 complete revolutions on the orifice of the right front and right rear teats were made with the moistened swab. Because of the small teat size of younger heifers, the entire length of the teat barrel was swabbed. Except for removal of gross debris, the teats were not cleaned if they had manure or dirt on them.

Sample Processing. Transport swabs were vigorously swirled in $2 \mathrm{~mL}$ of sterile $0.85 \%$ saline. Subsamples $(1 \mathrm{~mL})$ were plated on media selective for staphylococci [3M Petrifilm Staph Express Count System (STX); 3M Co., St. Paul, MN]. The transport swabs were then put

Table 2. Heifer inventory in sampled groups at midpoint in the study

\begin{tabular}{lcrr}
\hline Item & Herd 1 & Herd 2 & Herd 3 \\
\hline Hutch heifers $(<2$ mo) & 30 & 11 & 8 \\
Juvenile heifers on pasture $(2-6$ mo) & 40 & 22 & 15 \\
Heifers $>6$ mo, including breeding heifers & 60 & 32 & 60 \\
Bred heifers & 40 & 42 & 25 \\
Total & 170 & 107 & 108 \\
\hline
\end{tabular}


Table 3. Staphylococcus aureus isolation by dairy and site $^{1}$

\begin{tabular}{|c|c|c|c|c|}
\hline Sample site & Herd 1 & Herd 2 & Herd 3 & Total \\
\hline Cow milk (composites) & $14 / 117(12.0)$ & $21 / 118(17.8)^{3}$ & $17 / 148(11.5)$ & $52 / 383(13.6)$ \\
\hline \multicolumn{5}{|l|}{ Heifer site } \\
\hline Nostrils & $5 / 25(20.0)^{3}$ & $11 / 25(44.0)$ & $5 / 24(20.8)$ & $21 / 74(28.4)$ \\
\hline Teats & $2 / 25(8.0)$ & $14 / 25(56.0)$ & $11 / 24(45.8)$ & $27 / 74(36.5)$ \\
\hline \multicolumn{5}{|l|}{ Environmental } \\
\hline Bedding & $0 / 10(0)$ & $0 / 10(0)$ & $0 / 9(0)$ & $0 / 29(0)$ \\
\hline Horn fly samples & $7 / 15(46.7)$ & $9 / 16(56.2)$ & $13 / 21(61.9)$ & $29 / 52(55.8)$ \\
\hline \multicolumn{5}{|l|}{ Human site } \\
\hline Hand & $5 / 12(41.7)$ & $1 / 12(8.3)$ & $0 / 14(0)$ & $6 / 38(15.8)$ \\
\hline Nostrils & $1 / 6(16.7)$ & $1 / 6(16.7)$ & $1 / 7(14.3)$ & $3 / 19(15.8)$ \\
\hline Total & $59 / 426(13.8)$ & $104 / 412(25.2)$ & $81 / 390(20.8)$ & $244 / 1,228(19.9)$ \\
\hline
\end{tabular}

${ }^{1}$ Results are presented as the number of positive samples/no. collected (\%).

${ }^{2}$ Colostrums from 44, 38, and 24 heifers for herds 1, 2, and 3, respectively. Total $=106$ heifers sampled.

${ }^{3}$ One sample had 2 genotypes.

${ }^{4}$ Two samples had 2 genotypes each.

into $3 \mathrm{~mL}$ of Vogel-Johnson (VJ) broth (Difco Laboratories Inc., 1984).

Both STX plates and VJ broths were incubated for $24 \mathrm{~h}$ at $37^{\circ} \mathrm{C}$. After incubation of STX plates, presumptive positive colonies were identified according to the manufacturer's instructions (3M Co., 2004). Positive colonies on the STX plates were confirmed by appearance on TSA with $5 \%$ sheep blood after 48 -h incubation at 36 to $37^{\circ} \mathrm{C}$. Isolates were identified as Staph. aureus as described above.

Redundant testing was done to avoid missing Staph. aureus. If all colonies on STX plates were negative, further screening was performed. The incubated VJ broths were plated on Baird-Parker agar (Baird-Parker Agar Base; Oxoid Ltd., Basingstoke, Hampshire, UK), supplemented with tellurite enrichment (BD Difco EY Tellurite Enrichment; Becton, Dickinson and Co.). Typical Staph. aureus colonies after 48-h incubation at 36 to $37^{\circ} \mathrm{C}$ were plated onto $\mathrm{VJ}$ agar for further confirmation. Typical colonies on VJ agar after further incubation were plated onto TSA with sheep blood for final identification.

Feed. Sterile gloves were worn and handfuls of feed approximately $500 \mathrm{~mL}$ were taken along the entire length of a bunk or feeder and placed into a gallon plastic bag. A sterile cotton swab moistened with sterile saline was also swabbed along the bottom of the bunk or feeder and then placed in the plastic bag with the feed samples. Feed samples were processed as described for bedding/soil.

Water. Water samples from heifer water troughs and buckets were collected in sterilized milk dilution bottles (205-mL wide-mouth dilution bottle; Nalgene
Nunc International Corp., Rochester, NY), with sterile cheesecloth over the top of the bottle to prefilter any large debris. A total volume of 100 to $200 \mathrm{~mL}$ was then filtered through a $0.45-\mu \mathrm{m}$ pore filter (Millipore Microfil V; Millipore Corp., Billerica, MA) and the filter was placed on an $\mathrm{mStaph}$ (BD Difco mStaphylococcus broth; Becton, Dickinson and Co.) broth pad. The plates were incubated at 36 to $37^{\circ} \mathrm{C}$ for $48 \mathrm{~h}$, but were checked for growth at $24 \mathrm{~h}$. The filter was removed and growth was scraped using a sterile tongue depressor into $5 \mathrm{~mL}$ of brain-heart infusion broth (BD BBL; Becton, Dickinson and Co.). A total of $0.1 \mathrm{~mL}$ was plated on Baird-Parker agar. Typical isolates from growth on the Baird-Parker agar at 36 to $37^{\circ} \mathrm{C}$ after 24 to $48 \mathrm{~h}$ were processed as described in the transport swab processing procedures.

Bedding. Sterile gloves were worn and handfuls of bedding (hutches and pens) or vegetation and soil (pasture and lots), each approximately $200 \mathrm{~mL}$ in volume, were taken along 2 intersecting transects forming an $\mathrm{X}$ drawn over the area(s) where the heifers lived, trying to get representative samples of the wettest and driest areas in the hutch/pen/pasture. For pastures, 3 handfuls were taken along each transect made over the surface of the entire pasture. The bedding was placed into gallon plastic bags (Ziploc; S. C. Johnson \& Son Inc., Racine, WI), and hand-mixed for $30 \mathrm{~s}$. A 20-g subsample of mixed bedding was taken from the bag and then placed into a quart plastic bag (Ziploc). Sterile $0.85 \%$ saline $(100 \mathrm{~mL})$ was then added to the bag and vigorously mixed for $30 \mathrm{~s}$. Solids were allowed to settle and a representative 5 - $\mathrm{mL}$ sample of the saline/bedding liquid was filtered through a $5-\mu M$ syringe membrane filter (Acrodisc; Pall Corp., Cornwall, UK). The saline 
bedding $(0.1 \mathrm{~mL})$ was plated onto Baird-Parker and VJ agars. Staphylococcus aureus colonies were identified as previously described.

\section{Human Sampling}

Nostrils and hands of consenting milkers on the 3 dairies were sampled in the intermilking period using sterile transport media swabs (BD BBL Culture Swab; Becton, Dickinson and Co.). Transport swabs were processed as described previously.

Nostrils. A single dry transport swab was inserted 2 $\mathrm{cm}$ into each nostril and rotated around the circumference against the anterior mucosa for $3 \mathrm{~s}$ (CDC, 2000).

Hands. A transport swab moistened with sterile saline was rubbed in a straight line on the palm side of the hand from the point of the finger to the middle of the flexor surface of each finger. The hand was then held flat and the same swab was rubbed around the circumference of the hand going in and out between each finger. The back of the hand was then swabbed with the same swab from the point of the finger to the middle of the back of the hand. The same swab was then rubbed underneath the fingernail of each finger. Left and right hands were sampled separately.

\section{Horn Flies}

Horn flies were captured with a sweep net (student aerial insect nets; BioQuip Products Inc., Rancho Dominguez, CA) from the backs (or undersides) of milking cows and heifers either in the field or in the barn. Nets were disinfected between collections by spraying with disinfectant (HDQ Neutral One-Step Disinfectant; Spartan Chemical Co. Inc.), followed by $100 \%$ isopropanol or ethanol. Groups of flies swept off individual cows or heifers were placed in quart plastic bags (Ziploc). A subsample of 5 horn flies from each cow was placed into a $1.5-\mathrm{mL}$ microcentrifuge tube containing $300 \mu \mathrm{L}$ of sterile $0.85 \%$ saline and was thoroughly macerated on ice using a sterile electric pestle (Pellet Pestles Cordless Motor and Pellet Pestles; Kimble Kontes LLC, Vineland, NJ) for $30 \mathrm{~s}$. Fly debris was pushed to the bottom of microcentrifuge tube and $0.1 \mathrm{~mL}$ of the supernatant was plated on Baird-Parker agar. After 24 to $48 \mathrm{~h}$ at 36 to $37^{\circ} \mathrm{C}$ incubation, colonies typical of Staph. aureus were processed as described above.

\section{Storing Staph. aureus Isolates}

All Staph. aureus isolates were maintained frozen at $-75^{\circ} \mathrm{C}$ in brain heart infusion with $15 \%$ sterile glycerol.

\section{PFGE}

Preparation of bacterial genomic DNA, digestion by SmaI, and PFGE were performed according to methods modified from the Centers for Disease Control (Atlanta, GA) methods (McDougal et al., 2003). Digested fragments were separated by PFGE with a ramped pulse of 5 to $40 \mathrm{~s}$ at $200 \mathrm{~V}$ for $21 \mathrm{~h}$ at $14^{\circ} \mathrm{C}$ (Chef-DR II PFGE system; Bio-Rad Laboratories Inc., Hercules, CA). Gels were stained in a $0.1 \%$ ethidium bromide solution for $20 \mathrm{~min}$ and then destained in distilled water for $1 \mathrm{~h}$. Stained gels were digitally photographed and the photographs processed and dendrograms made using gel analysis and comparison software (BioNumerics; Applied Maths Inc., Austin, TX). Similarity coefficients were calculated and dendograms constructed using the Dice coefficient and unweighted pair group method with arithmetic means, respectively, with an optimization value of $1.0 \%$ and a position tolerance of $0.65 \%$.

\section{Definition of Genotype}

Isolates were considered to have indistinguishable genotypes if PFGE band patterns were identical. Genotypes grouping above $80 \%$ on the dendrogram (Applied Maths Inc., 2005) were considered members of the same genotype group or cluster of similarity (van Belkum et al., 2007). On the basis of the above definition, 12 genotype groups were identified (van Belkum et al., 2007).

\section{Statistical Analysis}

Prevalence of Staph. aureus for the different sample types was estimated and descriptive statistics were obtained. Differences in prevalence of Staph. aureus by herd for different sample types were evaluated using the chi-squared test or Fisher's exact test (SAS 9.1.3, 20022003; SAS Institute Inc., Cary, NC). Two univariate logistic regression models were developed to determine if Staph. aureus was as likely to be found in hornflies as in milk or colostrum. The models were simple with 1 main effect (i.e., milk or colostrum). Herd of origin of the sample was added to the model and evaluated as a possible confounder. Confounding was defined as a change of 2 units in any direction of the main-effect model odds ratio estimate. Colostrum samples were collected from quarters and there was more than 1 sample per heifer. We collapsed the quarter samples and recoded them as Staph. aureus negative or positive on a heifer basis. In the case of repeated milk samples for cows for which 2 different Staph. aureus genotypes were found, each animal was represented only 1 time in the data, as both results were positive for Staph. 
aureus. This occurred 4 times, as noted in Table 3 . Statistical significance was set at a $P$-value of $P \leq 0.05$.

\section{RESULTS}

\section{Positive Samples by Herd}

As shown in Table 3, 244/1,228 (or 19.9\%) of samples were Staph. aureus positive. The percentage of samples Staph. aureus positive by sample type and herd are given in Table 3. Prevalence of Staph. aureus varied by herd for colostrum samples $(P=0.0010)$, mouth samples $(P=0.0026)$, teat samples $(P=0.0005)$, water and water swabs $(P=0.019)$, and horn fly samples $(P$ $=0.042$ ).

\section{Positive Samples by Type}

A total of $70 / 411(17.0 \%)$ colostrum quarter milk samples and 52/383 (13.6\%) cow composite-quarter milk samples were positive for Staph. aureus (Table 3 ). The percentages of heifer mouth, nostril, and teat samples positive for Staph. aureus by dairy are shown in Table 3 and Figure 2. The percentages of Staph. aureus-positive feed, water, and bedding samples by dairy are given in Table 3 and Figure 2. Staphylococcus aureus was found in 6/38 (15.8\%) hand samples and $3 / 19(15.8 \%)$ nostril samples, or a total of $9 / 57(15.8 \%)$ human samples (Table 3; Figure 2).

More than one-half $(29 / 52$, or $55.8 \%)$ of all horn fly samples were positive for Staph. aureus. The percentages of positive flies by dairy are given in Table 3 and Figure 2. Results from logistic regression models indicated that it was 5 and 8 times as likely to find Staph. aureus in horn flies as in colostrum and milk, respectively (odds ratio $=5$ and $95 \%$ confidence interval for the odds ratio $=1.69-6.78$; odds ratio $=8$ and $95 \%$ confidence interval for the odds ratio $=4.32-14.93$ ) Herd had no confounding effect.

\section{PFGE Results}

Figure 3 is a dendogram showing the relatedness of the 54 genotypes of the 248 Staph. aureus isolates from 12 genotype groups (A, B, C, D, E, F, G, H, J, K, N, and $\mathrm{S}$ ) found in the current study. Genotype groups $\mathrm{A}$, B, C, K, and N grouped above 84.1, 81.22, 80.1, 84.3, and $93.7 \%$, respectively. Groups B, C, and N were very closely related, diverging at $76.4 \%$.

\section{Genotypes of All Samples}

The genotype groups by sample type for each herd for the 248 Staph. aureus isolates obtained during the study are shown in Table 4. Genotype group B was most frequently represented, being $126 / 248$ (50.8\%) of isolate genotypes. The second most common genotype group was A, representing $61(24.6 \%)$ of the total isolates. Next, $25(10.1 \%)$ isolates were in group $\mathrm{N}$ and 17 isolates $(6.8 \%)$ were in genotype group C. Six (2.4\%) isolates were from group $\mathrm{K}$ and $1(0.4 \%), 2(0.8 \%)$, and $1(0.4 \%)$ each of groups $\mathrm{E}, \mathrm{H}$, and J, respectively.

\section{Details on Specific Genotypes}

A Genotypes. Of the 61 total A genotype isolates (Table 4), only 2 were associated with sources other than cattle. No human isolates and only 1 isolate each were found from the environment and from flies. Staphylococcus aureus found in colostrum and milk samples accounted for $47 / 61$ or $77.0 \%$ of genotype A isolates. They were also found, although less commonly, on heifer body sites.

$B$ Genotypes. The most common genotype found was from group B, representing 126 total isolates. Of the total, $61 / 126$ (or $48.4 \%$ ) were found in milk and colostrum samples. A total of 24/126 (or 19.0\%) of group $\mathrm{B}$ isolates were found in flies. Although less frequent,

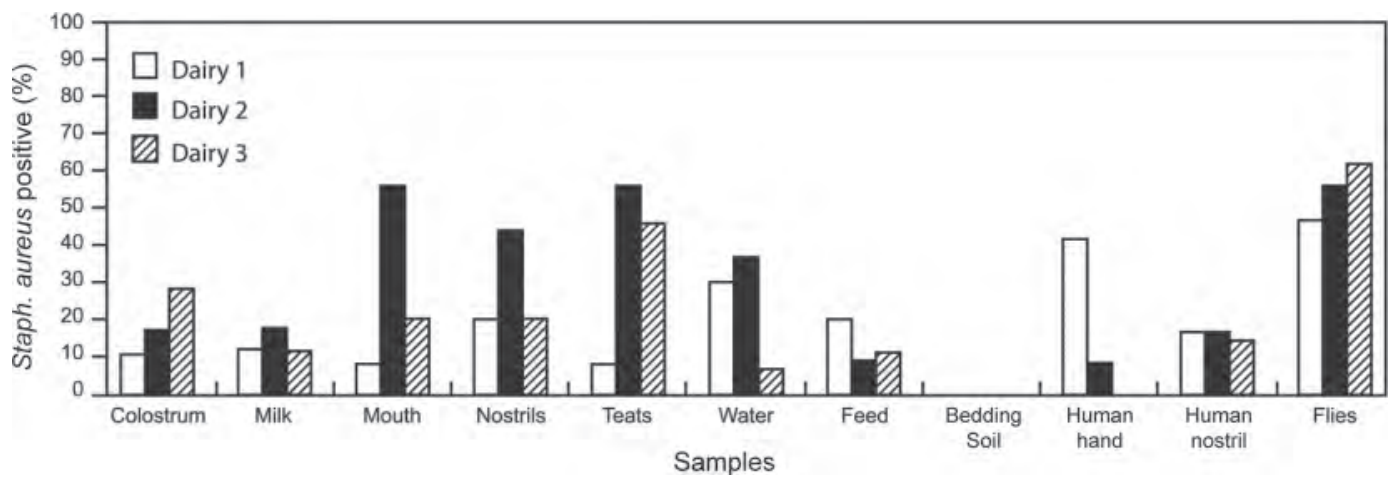

Figure 2. Percentage of sample types Staphylococcus aureus positive by dairy. 


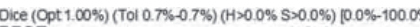

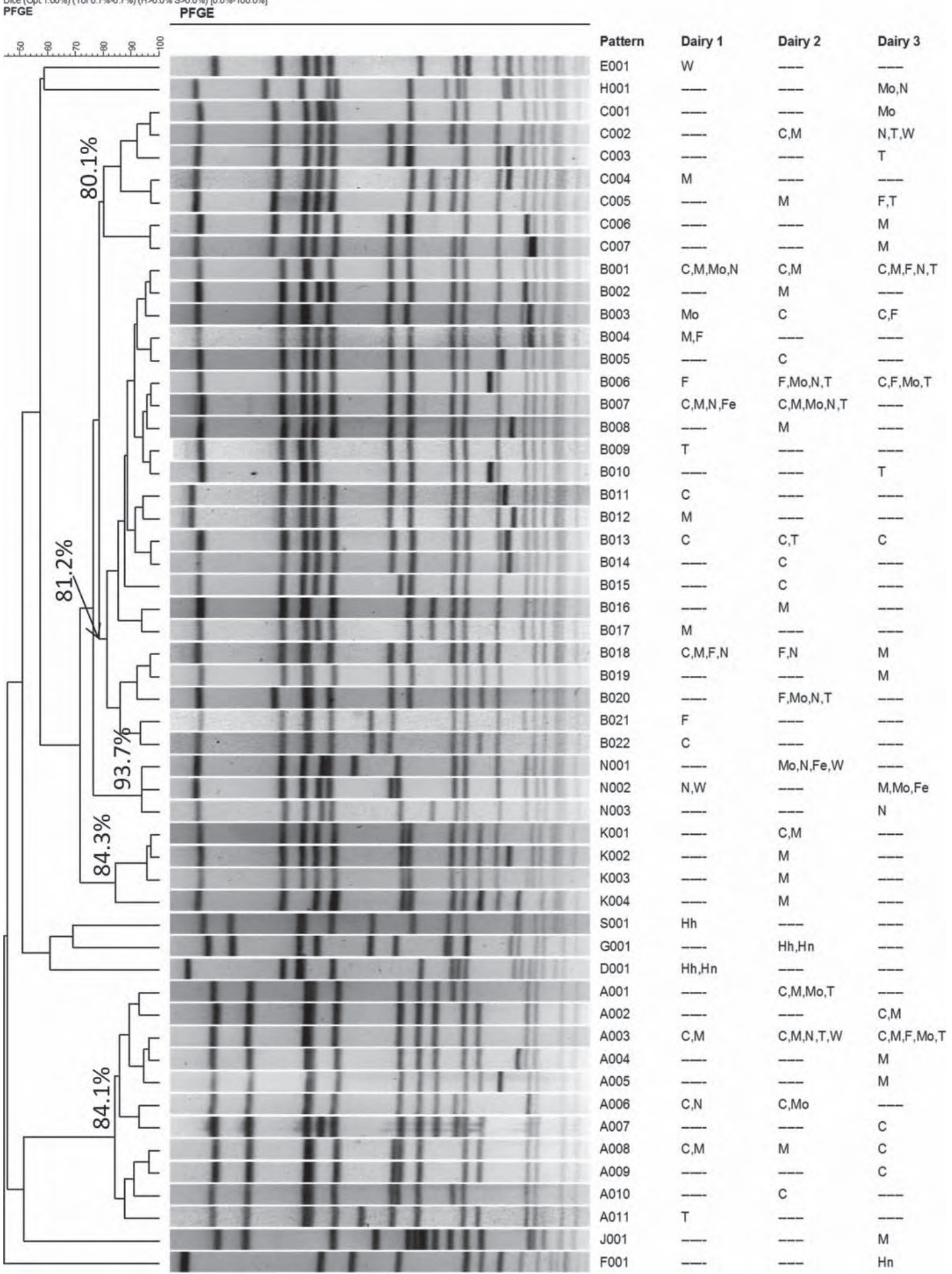

Figure 3. Dendrogram of genotype patterns and relatedness for Staphylococcus aureus isolates following SmaI digestion showing herds and sample sources. Pattern refers to Staph. aureus genotype. $\mathrm{C}=$ colostrum; $\mathrm{M}=$ milk; $\mathrm{F}=$ flies; $\mathrm{Mo}=$ mouth; $\mathrm{N}=$ nostrils; $\mathrm{T}=$ teats; Fe $=$ feed; $\mathrm{W}=$ water; $\mathrm{Hh}=$ human hand; $\mathrm{Hn}=$ human nostrils; PFGE = pulsed-field gel electrophoresis. 
Table 4. Staphylococcus aureus genotype groups (A-C, E, H, J, K, and N) by sample source for each herd (human Staph. aureus isolate genotype groups not shown)

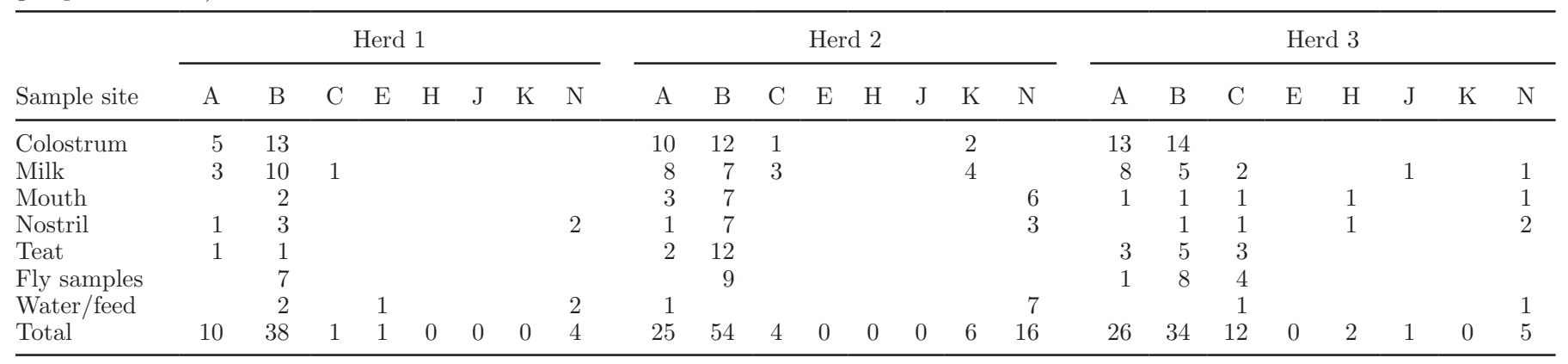

group B isolates were also found on heifer body sites on all dairies.

$\boldsymbol{N}$ Genotypes. Isolates of N genotypes were not found in flies and only 1 was found in colostrum or milk samples (Table 4). Most $\mathrm{N}$ isolates were found on heifer body sites, specifically mouths and nostrils, and from the environment.

Human Samples. Nine human samples were positive for Staph. aureus. These included 6 isolates from hands and 3 from the nostrils of 6 different milkers, 4 from herd 1 and 1 each from herds 2 and 3. Genotypes S001 $(\mathrm{n}=3)$, D001 $(\mathrm{n}=3)$, F001 $(\mathrm{n}=1)$, and G001 ( $=2$ ) found in human samples were completely different from all bovine and environmental isolates, based on PFGE analysis.

\section{DISCUSSION}

In our study, we found a mammary quarter prevalence of Staph. aureus of $17.0 \%$ overall in colostrum samples of heifers at calving and a $13.6 \%$ cow prevalence of Staph. aureus in lactating cows. These levels are higher than those of some previous reports in heifers. Roberson et al. (1994a), examining the occurrence of coagulase-positive staphylococci in primiparous cows at first parturition on 18 herds, categorized as either high $(>10 \%)$ or low $(<5 \%)$, found no significant difference in presence of Staph. aureus in heifers at parturition for high $(9.2 \%)$ compared with low Staph. aureus $(6.9 \%)$ herds. The prevalence in our study was also greater than the range for Staph. aureus in heifers at parturition reviewed by Fox (2009), with reported coagulase-positive staphylococci prevalences from 0.6 to $8.0 \%$. Therefore, as expected based upon the selection, the herds we studied had a high presence of Staph. aureus in lactating cows and in primiparous cows at first parturition.

We used PFGE to examine Staph. aureus strains from multiple sites, including cow milk and heifer colostrum samples, heifer body sites, flies, the environment, and humans. Our findings provided some interesting insights into the molecular epidemiology of Staph. aureus mastitis on these 3 dairies. First, heifer body sites were reaffirmed as representing potential sources of Staph. aureus for heifer IMI. Prior studies using a variety of methods have concluded that the teat skin is an important source of Staph. aureus for IMI in heifers (Davidson, 1961; Matos et al., 1991; Roberson et al., 1994b; Artursson et al., 2010; Rajala-Schultz et al., 2010). Investigation in a herd composed of monozygous twin cows pointed to the importance of both intramammary sites and the udder skin as sources of infection for other animals and to the effectiveness of hygiene systems in preventing new IMI (Davidson, 1961, 1963). In our study, the presence of Staph. aureus in heifer body sites included 28.4, 28.4, and $36.5 \%$ of all samples from mouths, nostrils, and teats, respectively (Table 3 ). The values were generally higher than those reported by Matos et al. (1991) in Kentucky, Roberson et al. (1994b) in Washington, and Artursson et al. (2010) in Sweden. Differences in microbiological methods, herd locations, and true prevalence of Staph. aureus could account for these differences. Our results are more similar to those of Rajala-Schultz et al. (2010), who reported isolation rates of $50.8 \%$ for mammary skin and $10.0 \%$ for oral mucosa of heifers. In their study, most heifer isolates were related to adult cow isolates as determined by PFGE. Finding similarity between Staph. aureus isolates in heifer samples and adult cow samples suggests that heifer body sites, primarily teats, were common potential sources of Staph. aureus for heifer IMI.

Water and water swabs and feed and feed swabs were positive for Staph. aureus in 25.0 and $13.3 \%$ of our samples, respectively. However, none of the bedding/ ground/vegetation samples were found to be positive. Artursson et al. (2010) found $19.8 \%$ of housing samples, $10.4 \%$ of water cups, $6.2 \%$ of samples from under rubber mats, $5.2 \%$ of feed samples, and $15.6 \%$ of bedding samples to be positive for Staph. aureus. This contrasts 
with Roberson et al. (1994b), who found housing, feedstuffs, air, water, equipment, and bedding to all be $\leq 2.1 \%$ positive for Staph. aureus. The same factors accounting for differences in heifer site isolations among studies could be operative here. Most (10 of 15 total) of the feed and water swabs were characterized as $\mathrm{N}$ genotypes, which were not found in flies and found only once in milk or colostrum, but which were found in heifer mouths and nostrils.

Staphylococcus aureus was found in 9/57 (15.8\%) human samples in this study. Importantly, all human isolates were entirely distinct, based on PFGE analysis, from those from any bovine or environmental sites. Shared strains of Staph. aureus have been reported between human beings and dairy cattle. For example, Juhász-Kasaznyitzky et al. (2007) found indistinguishable strains of methicillin-resistant Staph. aureus in cows with subclinical mastitis and a person working with the infected animals. Our findings, however, do not support conspecific sharing of strains between dairy cattle and humans in the herds that we studied.

Prior studies have implicated horn flies in mastitis transmission. Roberson et al. (1994b) reported finding $1.3 \%$ of insects (mainly flies) positive for Staph. aureus. Matos et al. (1991), however, found all of 30 fly samples negative in their study. Owens et al. (1998) found that Staph. aureus colonized horn flies and remained positive for Staph. aureus for up to $96 \mathrm{~h}$. Two Jersey heifers were exposed to infected horn flies and 3 of 4 exposed teats became infected with Staph. aureus. Scabs from naturally infected heifers were found to contain $>10^{7}$ cfu of Staph. aureus/mg. When horn flies fed on infected scabs, they in turn became colonized. The authors concluded that horn flies are capable of transmitting Staph. aureus IMI to heifers. In another study (Gillespie et al., 1999), Staph. aureus isolates from heifer mammary secretions, streak canals, and horn flies were compared using randomly amplified polymorphic DNA fingerprinting. The relationship between patterns from flies and heifers was examined. Of 56 Staph. aureus from heifers, 31 were subtype 1, 22 were subtype 2, and 3 were subtype 3 . Ten isolates from flies included 8 from subtype 1 and 2 from subtype 2 . Ten isolates from adult cows all belonged to a third and different subtype (subtype 3). The authors concluded that the results "suggest that horn flies may play an important role in transmission of $S$. aureus to nulligravid and primigravid heifers." In contrast to the Gillespie et al. (1999) study, our study showed that genotypes (i.e., group B isolates) were shared among flies, colostrum samples, and cow milk samples. Gillespie et al. (1999) found that most of the isolates from adult cows belonged to a different subtype than those found in heifers and flies.
The most important finding in the present study was the frequency with which horn fly samples were found positive for Staph. aureus (55.8\%) and the sharing of genotypes between Staph. aureus in flies and those found in heifer colostrum and cow milk samples. Group A genotypes were by far more commonly found in milk and colostrum samples as compared with flies (Table 4). Group B isolates, in contrast, were commonly found in milk and colostrum samples as well as flies (Table 4).

Genotype group B Staph. aureus isolates were also commonly found on heifer body sites. Indistinguishable isolates of type B genotypes were identified from flies, heifer body sites, and colostrum and milk samples (Figure 3). We conclude that flies and heifer body sites were found to harbor PFGE genotypes identical to those later isolated from heifer colostrum samples at parturition, supporting the assertion that flies and heifer body sites could be important sources of Staph. aureus for heifer IMI.

\section{CONCLUSIONS}

Three southeast US pasture-based herds with a presence of horn flies were studied during the summer, when horn flies are active. On the basis of lactating cow composite samples and quarter samples of heifers at freshening, the herds would be classified as herds with a high prevalence of Staph. aureus. Samples were taken from heifer body sites, the environment, horn flies, and from human workers. Staphylococcus aureus was consistently isolated from heifer body sites, occasionally from the environment, and from human workers. Identical or very similar genotypes were observed for Staph. aureus isolated from cow milk samples, heifer colostrum samples, heifer sites, and horn flies. We conclude that horn flies appear to be important in the spread of Staph. aureus mastitis in heifers. Further, our study demonstrated that the apparent behavior of Staph. aureus was genotype-specific. Genotype B isolates were commonly shared among milk and colostrum samples, horn flies, and body sites, whereas genotype $\mathrm{A}$ isolates were rarely (once) found in flies despite being common in milk and colostrum samples. Genotype $\mathrm{N}$ isolates were found on heifer body sites and the environment, but not in flies or milk and colostrum samples.

\section{ACKNOWLEDGMENTS}

The authors acknowledge the staffs of the respective dairies for their efforts on behalf of the project. The project was supported, in part, by the North Carolina Dairy Foundation Inc. (Raleigh) and by the US Department of Agriculture Animal Health Formula Funds. 
Support for K. Moury was provided by the NC State Veterinary Scholars Program and the Merck Foundation (Whitehouse Station, NJ).

\section{REFERENCES}

Applied Maths Inc. 2005. Pages 131-134 in BioNumerics Manual for Version 4.5. Applied Maths Inc., Austin, TX.

Artursson, K., A. Capurro, A. Aspán, H. Ericsson Unnerstad, and K. Persson Waller. 2010. Epidemiological studies of bovine mastitis. Pages 224-229 in Proc. 5th IDF Mastitis Conf., Christchurch, New Zealand. The New Zealand Veterinary Association Foundation for Continuing Education Inc. (VetLearn), Wellington, New Zealand.

Bruce, W. G. 1964. The history and biology of the horn fly, Haematobia irritans (Linnaeus); with comments on control. Technical Bulletin No. 157. North Carolina Agricultural Experiment Station and Entomology Research Division, Agricultural Research Service, United States Department of Agriculture; and Department of Entomology, North Carolina State University, Raleigh.

CDC (Centers for Disease Control). 2000. Specimen Collection Procedures Manual. Accessed June 14, 2012. http://www.cdc.gov/nchs/ data/nhanes/nhanes_01_02/specimen_collection_year_3.pdf

Davidson, I. 1961. Observations on the pathogenic staphylococci in a dairy herd during a period of six years. Res. Vet. Sci. 2:22-40.

Davidson, I. 1963. Experiments on controlling staphylococcal mastitis. Res. Vet. Sci. 4:64-76.

Difco Laboratories Inc. 1984. Pages $122-123$ and 1,046 in Difco Manual. 10th ed. Difco Laboratories Inc., Detroit, MI.

Fox, L. K. 2009. Prevalence, incidence and risk factors of heifer mastitis. Vet. Microbiol. 134:82-88.

Fox, L. K., K. W. Bayles, and G. A. Bohach. 2001. Staphylococcus aureus mastitis. Pages 271-294 in Staphylococcus aureus Infection and Disease. A. L. Honeyman, H. Friedman, M. Bendinelli, ed. Kluwer Academic/Plenum Publishers, New York, NY.

Gillespie, B. E., W. E. Owens, S. C. Nickerson, and S. P. Oliver. 1999. Deoxyribonucleic acid fingerprinting of Staphylococcus aureus from heifer mammary secretions and from horn flies. J. Dairy Sci. 82:1581-1585.

Haveri, M., M. Hovinen, A. Roslöf, and S. Pyörälä. 2008. Molecular types and genetic profiles of Staphylococcus aureus strains isolated from bovine intramammary infections and extramammary sites. J. Clin. Microbiol. 46:3728-3735.

Hogan, J. S., R. N. González, R. J. Harmon, S. C. Nickerson, S. P Oliver, J. W. Pankey, and K. L. Smith. 1999. Laboratory Handbook on Bovine Mastitis. Revised ed. National Mastitis Council Inc., Madison, WI.

Juhász-Kaszanyitzky, É., S. Jánosi, P. Somogyi, A. Dán, L. van der Graaf-van Bloois, E. van Duijkeren, and J. A. Wagenaar. 2007. MRSA transmission between cows and humans. Emerg. Infect. Dis. 13:630-632.

Lombard, J., T. Van Slyke, F. Welcome, Y. Schukken, and C. Kopral. 2008. Prevalence of contagious mastitis pathogens on US dairy operations. Pages 170-171 in Nat. Mast. Counc. Ann. Mtg. Proc. New Orleans, LA. National Mastitis Council Inc., Madison, WI.
Matos, J. S., D. G. White, R. J. Harmon, and B. E. Langlois. 1991 Isolation of Staphylococcus aureus from sites other than the lactating mammary gland. J. Dairy Sci. 74:1544-1549.

McDougal, L. K., C. D. Steward, G. E. Killgore, J. M. Chaitram, S. K. McAllister, and F. C. Tenover. 2003. Pulsed-field gel electrophoresis typing of oxacillin-resistant Staphylococcus aureus isolates from the United States: Establishing a national database. J. Clin. Microbiol. 41:5113-5120.

3M Co. 2004. Page 4 in 3M Petrifilm Staph Express Count System insert. 3M Co., St. Paul, MN.

Merck \& Co. Inc. 2005. Horn flies. Pages 721-722 in The Merck Manual. 9th ed. C. M. Kahn, ed. Merck \& Co. Inc., Whitehouse Station, NY.

NMC (National Mastitis Council). 2012. National Mastitis Council website. Accessed Jun. 14, 2012. http://www.nmconline.org/articles/staphepidem.htm.

Oliver, S. P., B. E. Gillespie, S. J. Headrick, M. J. Lewis, and H. H. Dowlen. 2005. Prevalence, risk factors, and strategies for controlling mastitis in heifers during the periparturient period. Int. J. Appl. Res. Vet. Med. 3:150-162.

Owens, W. E., S. P. Oliver, B. E. Gillespie, C. H. Ray, and S. C. Nickerson. 1998. Role of horn flies (Haematobia irritans) in Staphylococcus aureus-induced mastitis in dairy heifers. Am. J. Vet. Res. 59:1122-1124.

Rajala-Schultz, P. J., S. Holland, J. B. Walker, F. J. DeGraves, W. A Gebreyes, J. Mathews, J. S. Hogan, and L. da Costa. 2010. Crosssectional sampling of dairy heifers and cows to assess genotypic diversity of Staphylococcus aureus in a dairy herd. Pages 220-223 in Proc. 5th IDF Mastitis Conf., Christchurch. New Zealand. The New Zealand Veterinary Association Foundation for Continuing Education Inc. (VetLearn), Wellington, New Zealand.

Roberson, J. R., L. K. Fox, and D. D. Hancock. 1992. Probable source(s) of Staphylococcus aureus infecting mammary glands of dairy heifers prepartum. J. Dairy Sci. 75(Suppl. 1):162. (Abstr.)

Roberson, J. R., L. K. Fox, D. D. Hancock, C. C. Gay, and T. E. Besser. 1994a. Coagulase-positive Staphylococcus intramammary infections in primiparous dairy cows. J. Dairy Sci. 77:958-969.

Roberson, J. R., L. K. Fox, D. D. Hancock, J. M. Gay, and T. E. Besser. 1994b. Ecology of Staphylococcus aureus isolated from various sites on dairy farms. J. Dairy Sci. 77:3354-3364.

Roberson, J. R., L. K. Fox, D. D. Hancock, J. M. Gay, and T. E. Besser. 1998. Sources of intramammary infections from Staphylococcus aureus in dairy heifers at first parturition. J. Dairy Sci. 81:687-693.

Soulsby, E. J. L. 1968. Genus: Haematobia. Pages 420-421 in Helminths, Arthropods, and Protozoa of Domesticated Animals. 6th ed. E. J. L. Soulsby, ed. Williams \& Wilkins, Baltimore, MD.

van Belkum, A., P. T. Tassios, L. Dijkshoorn, S. Haeggman, B. Cookson, N. K. Fry, V. Fussing, J. Green, E. Feil, P. Gerner-Smidt, S Brisse, and M. Struelens. 2007. Guidelines for the validation and application of typing methods for use in bacterial epidemiology. Clin. Microbiol. Infect. 13(Suppl. 3):1-46.

Wegener, H. C., P. Nielsen, and V. T. Rosdahl. 1993. Staphylococcus aureus mastitis in heifers. An epidemiological study by conventional and molecular typing methods. Dansk Veterinærtidsskrift $76: 457-461$. 